\title{
TECNOLOGIAS AMBIENTAIS E OS IMPACTOS NO DESEMPENHO ECONÔMICO-FINANCEIRO: O CASO DA CELULOSE IRANI S/A
}

\section{ENVIRONMENTAL TECHNOLOGIES AND IMPACTS ON ECONOMIC AND FINANCIAL PERFORMANCE: THE CASE OF CELULOSE IRANI S / A}

\section{Fábio Lazzarotti}

Doutor em Administração e Turismo pela Universidade do Vale do Itajaí; Coordenador do Mestrado Profissional em Administração da UNOESC fabio.lazzarotti@unoesc.edu.br

\section{Simone Sehnem}

Doutora em Administração e Turismo pela Universidade do Vale do Itajaí; Professora do Mestrado Profissional em Administração da UNOESC

simonesehnem_adm@yahoo.com.br

\section{Yeda Maria Pereira Pavão}

Doutora em Administração e Turismo pela Universidade do Vale do Itajaí; Professora da UNESPAR

yedapavao@gmail.com

\section{Anete Alberton}

Doutora em Engenharia de Produção pela Universidade Federal de Santa Catarina; Professora do Programa de Pós-Graduação em Administração da UNIVALI anete@univali.br

\section{Contextus}

ISSNe 2178-9258

Organização: Comitê Científico Interinstitucional Editor Científico: Marcelle Colares Oliveira Avaliação : Double Blind Review pelo SEER/OJS Revisão: Gramatical, normativa e de formatação

Recebido em 23/04/2012 Aceito em 10/02/2014 $2^{\mathrm{a}}$. versão aceita em 17/03/2014

\section{Sidnei Marinho}

Doutor em Engenharia de Produção pela Universidade Federal de Santa Catarina; Professor do Programa de Pós-Graduação em Administração da UNIVALI

sidnei@univali.br

\section{RESUMO}

Este artigo analisa o impacto das tecnologias ambientais no desempenho econômico-financeiro de uma empresa de papel e celulose. Entre os investimentos, delimitaram-se neste estudo dois projetos implementados pela empresa: a usina de cogeração de energia e a modernização da Estação de Tratamento de Efluentes. Para a coleta de dados, a análise documental e de conteúdo foi realizada por meio de procedimento descritivo-quantitativo, a partir dos dados secundários disponíveis nos relatórios de sustentabilidade e de demonstrações financeiras. Os investimentos ambientais parecem ter impactado favoravelmente no desempenho econômico-financeiro da organização, levando-se em conta somente os indicadores de valor econômico e de geração de caixa, em específico o MVA e o EBITDA, não obstante a crise financeira internacional. Contudo, há evidências de que os investimentos ambientais se coadunam com a política de mitigação dos impactos ambientais durante o processo produtivo da empresa Irani. Isso se comprova pelos resultados obtidos até o momento, que evidenciam que os projetos de MDL, desde sua consolidação, possibilitaram a redução da emissão de aproximadamente 200 mil toneladas de $\mathrm{CO}_{2}$ ao ano.

Palavras-chave: Tecnologias ambientais. Desempenho. Indicadores econômico-financeiros. Relatórios de sustentabilidade. Demonstrações financeiras.

\begin{abstract}
This article analyzes the impact of environment technologies in the financial performance of company's pulp and paper. Among the investments it was delimited in this study, two projects implemented by the company: the plant cogeneration power station and upgrading of sewage treatment station. To collect data, document analysis and content was conducted by means of descriptive and quantitative procedure, based on secondary data available in sustainability reporting and financial statements. Environmental investments seem to have favorably impacted the financial performance of the organization, taking into account only the indicators of economic value and cash flow, in particular MVA and EBITDA despite the international financial crisis. However, there is evidence that environmental investments are in line with the policy to mitigate environmental impacts during the production process of the company Irani. This is proved by the results obtained so far, which shows that the $\mathrm{CDM}$ projects since its consolidation enabled a reduction in the emission of approximately 200000 tonnes of $\mathrm{CO} 2$ a year.
\end{abstract}

Keywords: Environmental technologies. Performance. Economic-financial indicators. Sustainability reports. Financial statements. 


\section{INTRODUÇÃO}

As tecnologias ambientais são investimentos em tecnologias de operações que visam aumentar o desempenho ambiental de uma operação. São elas que asseguram a rentabilidade e a competitividade da maioria das empresas industriais (GRAVONSKI, 2009). Vários estudos estabelecem nesse processo análises dos impactos no desempenho econômico-financeiro e avaliam cada vez mais a estrutura adotada, no intuito de analisar o posicionamento das organizações diante da sua responsabilidade associada a esse assunto (KEATS; HITT, 1988; OLSON, 1991; MAZON, 1992; JAGGI; FREEDMAN, 1992; ARAGON-CORREA; LOPES, 2007; CARDOSO; MARINHO, 2008; RIBEIRO et al., 2009).

Conforme Gasi e Ferreira (2006), antes da década de 1970 não havia a preocupação por parte das empresas em efetuar o controle ambiental, e os órgãos precursores no controle da poluição foram estruturados no início dessa década. Os poluentes eram gerados e descartados na natureza sem maiores preocupações. A partir de então, as legislações ambientais foram organizadas, e as atividades de monitoramento da qualidade ambiental, de licenciamento e de fiscalização das indústrias foram iniciadas. Alberton (2003) destaca que pela primeira vez, no ano de 1972, em uma conferência internacional, foram discutidos aspectos técnicocientíficos, sociais, políticos e econômicos que se coadunam com o meio ambiente.

Cardoso e Marinho (2008) afirmam que a legislação ambiental se tornou cada vez mais restritiva no que diz respeito ao manuseio de produtos e à disposição dos resíduos na natureza. Além disso, tem ocorrido o aumento da responsabilidade civil e criminal, com a cobrança de eventuais prejuízos causados pelas empresas ao meio ambiente, à saúde e à segurança das pessoas. Consequentemente, as tecnologias de fim de tubo passam a conquistar o seu espaço e, em conformidade com Tigre (1994, p. 53): “[...] as tecnologias end-of-pipe transferem custos diretamente para o produto, seja pela adoção de acessórios que os tornem menos poluentes, seja pelo repasse do custo de minimização dos rejeitos no seu processo produtivo".

Diante desse escopo, passaram a surgir diversas tecnologias que expressam a minimização do impacto ambiental gerado pelas atividades produtivas. Seiffert (2009) destaca os Mecanismos de Desenvolvimento Limpo (MDL), que consistem em projetos que visam a implantação de alterações em processos produtivos ou a realização de modificações, com o intuito de elevar a sua 
sustentabilidade. Consequentemente, são processos produtivos mais limpos, obtidos por meio da implementação de novas tecnologias, que ofereçam a possibilidade de elevar a sustentabilidade da organização.

Para Corazza (2003), o conceito de tecnologias "mais limpas" não se relaciona a soluções definitivas, mas, ao contrário, apresenta-se em coevolução com a própria dinâmica tecnológica, com os padrões de qualidade ambiental e, por conseguinte, com a construção sociopolítica desses padrões. Mazon (1992) destaca que as tecnologias verdes irão fornecer uma ampla quantidade de serviços ambientais que englobam desde a transformação de resíduos tóxicos até a restauração de ecossistemas degradados. Um forte motivador para a implantação de tecnologias ambientais é o lucro. A criação de uma tecnologia ambientalmente correta e avançada também pode tornar-se uma grande oportunidade de negócios. Tal tecnologia, em geral, advém de reprojetos de manufatura associados à reutilização de materiais residuais, de eficiência energética, de energia renovável, da agricultura sustentável, do transporte eficiente, de construções sustentáveis (MAZON, 1992).

A partir desse contexto, apresentase o seguinte questionamento: qual $o$ impacto das tecnologias ambientais no desempenho econômico-financeiro de uma empresa? Para responder a essa questão, o presente artigo traz como objeto de estudo a empresa Celulose Irani S/A, delimitado pelas tecnologias ambientais adotadas pela organização, em especial por dois projetos de Mecanismos de Desenvolvimento Limpo - MDL: usina de cogeração de energia e modernização da estação de tratamento de efluentes.

O objetivo principal do estudo é analisar o impacto das tecnologias ambientais no desempenho econômicofinanceiro de uma empresa do setor de papel e celulose. Pretende-se também: a) descrever as principais tecnologias ambientais implantadas no processo de produção da Irani (MDL e Inventário de Emissões de Gases de Efeito Estufa GEE); b) relatar os impactos que a implantação das tecnologias ambientais teve no que diz respeito ao quesito econômico (redução de gastos/otimização de processos/lucro), com base nos relatórios de sustentabilidade; c) analisar o comportamento dos principais indicadores financeiros da organização no período de 2000 a 2009; d) verificar se há um padrão econômico associado aos investimentos em tecnologias ambientais, em relação aos diferentes períodos de implantação. 


\section{REFERENCIAL TEÓRICO}

Nesta seção são descritos os aspectos teóricos que fundamentam a pesquisa. Abordam-se as tecnologias ambientais, os conceitos e a finalidade de sua aplicação nas organizações, seguido dos indicadores utilizados para analisar o desempenho financeiro das empresas. Ao final desta seção, apresentam-se vários estudos que objetivaram relacionar investimentos ambientais com desempenho.

\subsection{Tecnologias Ambientais}

As ferramentas ambientais que abordam a produtividade dos recursos, denominadas de Ecoeficiência, Produção mais Limpa (PML), Ecologia Industrial e Produção Limpa são responsáveis pela redução do uso de materiais e energia e integram a prevenção da poluição com o processo de produção. Em relação ao sistema de produção tradicional, a prerrogativa vigente é o controle da poluição, em que são estabelecidos padrões de poluição para os meios físicos e bióticos.

Todavia, a adoção de qualquer um desses conceitos requer uma profunda mudança no desenvolvimento de todas as atividades das empresas (CARDOSO; MARINHO, 2008). Trata-se, principalmente, da mudança do paradigma cultural, que engloba preceitos, padrões de ação e formas de trabalhar, cujos princípios abrangem a prevenção, a precaução, o controle democrático e a integração.

Mello (2002) menciona as habilidades básicas e o conhecimento tácito da empresa. Tratam-se de aspectos relacionados ao "aprender fazendo", isto é, associados às rotinas organizacionais, vistos como difíceis de reproduzir e pautados na experiência acumulada pelas pessoas, refinada pelo exercício da prática. A ferramenta considerada mais eficiente, por incorporar todos os princípios supramencionados, é a PML (Cardoso; Marinho, 2008).

Lemos (1998), com base em estudos de autores que tratam sobre implementação de PML (BERKEL, 1995; CHRISTIE et al., 1995; FRESNER, S/D; SCHIMIDLHEINY, 1992; UNIDO/UNEP, 1995a), elencou possíveis resultados tangíveis e intangíveis que as empresas poderão obter ao implementar a ferramenta, representada no Quadro 1 a seguir. 
Quadro 1 - Possíveis resultados tangíveis e intangíveis obtidos pelas empresas com a implementação da Produção mais Limpa (PML)

\begin{tabular}{|c|c|}
\hline RESULTADOS TANGÍVEIS & RESULTADOS INTANGIVEIS \\
\hline $\begin{array}{l}\text { 1. Geração de inovações tecnológicas de processo, de } \\
\text { produto e gerencial. } \\
\text { 2. Benefícios advindos de vantagens comerciais } \\
\text { (concessão de financiamentos, obtenção de seguros } \\
\text { com taxas mais ativas, facilidade para tornar-se } \\
\text { fornecedor de grandes empresas). } \\
\text { 3. Melhoria da competitividade (através da redução de } \\
\text { custos ou da melhoria da eficiência). } \\
\text { 4. Redução de custos com matérias-primas, insumos e } \\
\text { energia. } \\
\text { 5. Ocorrência de melhorias econômicas de curto prazo. } \\
\text { 6. Novas oportunidades de negócios. } \\
\text { 7. Minimização dos riscos no campo das obrigações } \\
\text { ambientais. } \\
\text { 8. Redução dos encargos ambientais causados pela } \\
\text { atividade industrial. }\end{array}$ & $\begin{array}{l}\text { 1. Desenvolvimento econômico mais sustentado. } \\
\text { 2. Melhoria da qualidade ambiental do produto. } \\
\text { 3. Melhoria da imagem pública das empresas. } \\
\text { 4. Aumento da eficiência ecológica. } \\
\text { 5. Melhoria das condições de trabalho dos } \\
\text { empregados. } \\
\text { 6. Aumento da motivação dos empregados. } \\
\text { 7. Diversidade de benefícios para as empresas bem } \\
\text { como para a sociedade. } \\
\text { 8. Indução do processo de inovação dentro das } \\
\text { empresas. } \\
\text { 9. Aumento da segurança dos consumidores dos } \\
\text { produtos. }\end{array}$ \\
\hline
\end{tabular}
Fonte: Adaptado de Lemos (1998, p. 32).

A compreensão real do que é Produção Limpa pode tornar-se um diferencial competitivo, e incorporá-la à estratégia de produção requer a percepção do que seja um novo paradoxo ambiental, capaz de melhorar o desempenho das organizações (GONÇALVES, 1998). Nesse âmbito, o setor de papel e celulose, no entendimento de Ribeiro et al. (2009), é considerado de alto impacto ambiental (BRASIL, Lei 10165/2000), pois seu processo operacional tem uma estreita relação com o meio socioambiental, especialmente com a dimensão ambiental. Além disso, o plantio das sementes, os tratos culturais e a manutenção da planta até a fase adulta, assim como o manejo do solo, para evitar a exaustão, e o aumento da produtividade são práticas que ocasionam degradações quando não conduzidas corretamente. Igualmente, as interferências climáticas, os instrumentos de corte, a retirada da madeira da floresta, a forma de tratamento dos resíduos da matéria-prima natural não aproveitada, bem como os resíduos químicos utilizados no processamento da madeira e da celulose, são etapas do processo operacional do setor de papel e celulose que exercem grande influência sobre o meio socioambiental.

Quanto aos aspectos formais, as empresas emitem relatórios de sustentabilidade, os quais são uma importante base de informações de organizações que disponibilizam dados sobre suas ações relacionadas ao investimento com a preservação ambiental. Além dessa socialização, as empresas participantes poderão garantir a confiança de stakeholders relacionados ao setor onde atuam. 


\subsection{Indicadores de desempenho econômico-financeiro}

Existem diferentes dimensões na definição de um construto para desempenho econômico-financeiro. Venkatraman e Ramanujam (1986) entendem que ainda não há um consenso na academia em relação a esse construto, em especial sobre a determinação de indicadores válidos para melhor representar a eficácia organizacional. Conforme Keats e Hitt (1988), o desempenho econômico-financeiro é um conceito difícil, tanto em termos de definição como de medição.

As dimensões do desempenho financeiro utilizadas por Keats e Hitt (1988) abordam a dimensão do desempenho operacional e a dimensão baseada no mercado. A primeira recai em uma avaliação do passado e do presente da organização, enquanto a última faz uma análise orientada para o futuro. Santos (2008) e Brito, Morganti e Brito (2009) sugerem três dimensões em termos de medidas de desempenho financeiro: mercado, crescimento e lucratividade. $\mathrm{Na}$ dimensão de mercado, Santos (2008) propõe alguns indicadores: lucro por ação, valorização das ações, dividendos sobre preço da ação, volatilidade das ações, valor de mercado/valor patrimonial e Q de Tobin. Análogo aos indicadores propostos por Santos (2008), Hoji (2004) descreve o Economic Value Added (EVA) e o Market Value Added (MVA) para analisar o desempenho financeiro baseado na geração de valor econômico.

O EVA não é uma medida de desempenho recente. Conhecido também como lucro residual, seu conceito já era trabalhado na área das finanças desde o início do século XX, a partir das ideias do economista Alfred Marshall. Porém, popularizou-se somente a partir dos anos 80 , quando a empresa de consultoria Stern Stewart \& Company patenteou a metodologia (SANTOS; WATANABE, 2005). Em linhas gerais, o EVA mostra se a empresa está criando ou destruindo valor. Kramer e Pushner (1997) entendem que o EVA é uma medida de desempenho operacional essencial para qualquer empresa que apresenta preocupação com a maximização de riqueza dos seus acionistas. A razão dessa afirmação está embasada no custo do capital próprio levado em conta no cálculo do EVA, de modo a verificar o valor efetivamente acrescentado ao patrimônio líquido em determinados períodos.

O MVA, Valor de Mercado Adicionado, é uma medida de desempenho que tem por base o mercado. $\mathrm{O}$ objetivo primário da maioria das empresas é maximizar a riqueza do acionista. A consolidação desse objetivo aufere 
benefícios a esse acionista e assegura a alocação de recursos escassos de forma eficiente. A riqueza do acionista é aumentada através da maximização da diferença entre o valor de mercado do capital dos acionistas e o montante de capital que eles investiram na empresa - o que se denomina de MVA (SANTOS; WATANABE, 2005).

Hoji (2004) salienta que a diferença entre o EVA e o MVA é que o primeiro mede o resultado do passado e no curto prazo e o segundo mede o resultado do futuro e no longo prazo, mas ambos têm por finalidade mensurar o valor adicionado aos proprietários. Além desses dois indicadores, o autor sugere ainda a utilização do Lucro antes dos Juros, Impostos sobre o Lucro, Depreciação e Amortização (Lajida), conhecido também pelo mercado por Earning Before Interest, Taxes, Depreciation and Amortization (EBITDA). Trata-se de um indicador que permite verificar se os ativos estão gerando caixa. De acordo com Hoji (2004, p.318), o

\section{EBITDA:}

É considerado pelos analistas financeiros o melhor indicador de geração de caixa operacional, pois considera em seu cálculo somente os resultados operacionais que afetam o caixa, desconsiderando as despesas e as receitas operacionais como a depreciação, amortização e exaustão, o resultado de equivalência patrimonial, as despesas e as receitas financeiras, outras receitas e despesas operacionais não rotineiras e, também, os impostos sobre o lucro (Imposto de Renda e Contribuição Social sobre o Lucro).
Quanto à dimensão do crescimento, Santos (2008) apresenta os indicadores de market share, lucro líquido, ativo total, faturamento e número de funcionários. Essa dimensão, de acordo com Brito, Morganti e Brito (2009), estaria associada também ao conceito de vantagem competitiva desenvolvido por Porter (1985) e Besanko et al. (2006).

Contudo, das três dimensões apontadas por Santos (2008) e Brito, Morganti e Brito (2009), a mais explorada para avaliar o desempenho financeiro das organizações é a lucratividade. Segundo os autores supracitados, a lucratividade abrange medidas como retorno sobre os ativos, investimentos ou patrimônio. Entretanto, muitos autores entendem que essa dimensão é, conceitualmente, distinta de rentabilidade. Esta última, em geral, apresenta um conceito vinculado aos indicadores de retorno sobre os ativos e investimentos, enquanto a lucratividade se restringe ao lucro sobre as vendas (PERIN; SAMPAIO, 2004).

Há um conjunto amplo de indicadores que medem o desempenho financeiro quanto à rentabilidade a partir das demonstrações financeiras de uma organização. Assaf Neto e Lima (2009) destacam o Retorno sobre o Ativo (ROA), o Retorno sobre o Investimento (ROI), o Retorno sobre o Patrimônio Líquido (ROE) 
e a Lucratividade, concebida como rentabilidade das vendas.

O ROA, de acordo com Assaf Neto e Lima (2009), indica a taxa de retorno gerado pelas aplicações realizadas por uma empresa em seus ativos. Os autores salientam que o resultado não é influenciado pela forma como a empresa é financiada, sendo o resultado gerado exclusivamente pelo investimento de ativos. Deve responder a seguinte pergunta: a cada $\$ 1,00$ investido pela empresa em seus ativos, quanto ela gera de retorno?

O ROI é considerado por Assaf Neto e Lima (2009) um indicador alternativo ao uso do ROA. Tem por finalidade avaliar o retorno produzido pelo total dos recursos investidos por acionistas e credores do negócio. Segundo Hoji (2004), o ROI é tido por muitos analistas como a melhor medida de eficiência operacional. Entretanto, ele tem limitações na prática e deve ser usado juntamente com outros indicadores, assevera o autor.

O ROE é um indicador que mensura somente o retorno dos recursos investidos na empresa por seus acionistas ou proprietários. Ainda com base em Assaf Neto e Lima (2009), deve responder a seguinte pergunta: a cada $\$ 1,00$ de recursos próprios (patrimônio líquido) investido na empresa, quanto os acionistas obtêm de retorno? Salienta-se que o ROE deve ser comparado sempre com uma taxa mínima de retorno exigida pelo acionista. Trata-se do custo de oportunidade. O acionista, em geral, busca comparar o retorno com outros investimentos, esperando que, no mínimo, o retorno seja igual ao custo do capital praticado pelo mercado. No Brasil, pode-se comparar uma taxa de oportunidade levando em conta a taxa do Sistema Especial de Liquidação e de Custódia (Selic) adotada pelo Banco Central brasileiro. Essa taxa serve de balizamento para a maioria das operações financeiras no país.

\subsection{Estudos que relacionam tecnologias ambientais e desempenho econômico- financeiro das organizações}

Diversos estudos têm sido realizados para evidenciar a associação existente entre desempenho ambiental e desempenho econômico. Jaggi e Freedman (1992) utilizaram como variáveis-chave para o desempenho ambiental três medidas de poluição e taxas contábeis para o desempenho econômico. Concluíram não haver associação, no longo prazo, entre o desempenho ambiental e o econômico nas indústrias de papel e celulose. Porter e Van der Linde (1995) popularizaram uma visão diferente quanto aos investimentos. Os autores propuseram que os investimentos ambientais podem contribuir para a 
vantagem competitiva das organizações. A redução da poluição proporciona redução dos custos futuros e aumenta a eficiência, reduzindo a longevidade dos custos e minimizando as responsabilidades futuras. Desde essa publicação de Porter e Van der Linde (1995), a maioria das publicações confirmaram links diretos e positivos entre estratégia ambiental proativa e desempenho financeiro, explicadas, muitas vezes, pela geração de capacidades organizacionais (como a inovação contínua ou gerência de stakeholders), por meio de práticas ambientais (e reputação social e legitimação).

Hart e Ahuja (1996), por sua vez, desenvolveram uma pesquisa na qual buscaram mensurar o desempenho ambiental a partir da redução da emissão de resíduos tóxicos. Os autores utilizaram como variáveis de análise para o desempenho econômico o Retorno do Ativo, o Retorno das Vendas (ROS) e o Retorno do Patrimônio Líquido. Analisaram 127 empresas no período de 1989 a 1992 utilizando-se do método de regressão. Constataram não haver efeitos positivos do desempenho ambiental no desempenho econômico das empresas. A partir do estudo de Klassen e McLaughlin (1996), foi constatado que empresas obtiveram retornos anormais negativos e significativos quando foram publicadas notícias ambientais ruins sobre elas, tais como vazamento de óleo, e divulgados retornos positivos quando elas receberam prêmios/recompensas ambientais.

King e Lenox (2001), por seu turno, reiteraram que diversos estudos sugerem a tendência de firmas com alto desempenho a serem mais lucrativas, mas que persistem questionamentos acerca da natureza desse relacionamento. Nesse sentido, questionam se será mais forte o desempenho do ambiente e se essa performance realmente conduz a uma melhoria do desempenho financeiro ou se a relação observada é resultado de algum atributo subjacente a outros atributos da firma. Será que a firma precisa pagar para ter instalações limpas? Para esclarecer esses aspectos, os autores analisaram 652 firmas de manufatura dos Estados Unidos num período longitudinal de 1987 a 1996. Constataram a evidência de uma associação entre menor poluição e maior valorização financeira. Destacam-se alguns trabalhos desenvolvidos para identificar a relação entre o desempenho ambiental e o desempenho econômico, conforme Quadro 2, a partir de AragónCorrea e Rubio-López (2007). 
Quadro 2 - Trabalhos que versam sobre desempenho econômico e desempenho ambiental

\begin{tabular}{|c|c|}
\hline Estudos & $\begin{array}{c}\text { Relação estabelecida (enfoque) entre desempenho econômico e desempenho } \\
\text { ambiental }\end{array}$ \\
\hline $\begin{array}{l}\text { Wagner, Van Phu, } \\
\text { Azomahou e } \\
\text { Whermeyer (2002) }\end{array}$ & $\begin{array}{l}\text { Pesquisaram } 37 \text { empresas da indústria de papel localizadas na Alemanha, na Itália, no } \\
\text { Reino Unido e na Holanda e evidenciaram um trade-off entre o retorno sobre o capital } \\
\text { próprio empregado e o desempenho ambiental. }\end{array}$ \\
\hline $\begin{array}{l}\text { Thornton, Kagan e } \\
\text { Gunningham } \\
\text { (2003) }\end{array}$ & $\begin{array}{l}\text { Constataram, por meio de um estudo de casos de } 14 \text { empresas da indústria de papel do } \\
\text { Canadá, da Austrália, da Nova Zelândia e dos E.U.A., que as diferenças no } \\
\text { desempenho ambiental das empresas não foram consistentemente correlacionadas com } \\
\text { a rentabilidade ou as vendas da empresa-mãe. }\end{array}$ \\
\hline Banse & $\begin{array}{l}\text { Encontrou uma relação negativa entre o desempenho financeiro como variável de } \\
\text { controle e sustentabilidade das empresas de desenvolvimento. }\end{array}$ \\
\hline $\begin{array}{l}\text { Alberton e Costa Jr. } \\
\text { (2007) }\end{array}$ & $\begin{array}{l}\text { Investigaram se a implantação e a certificação de um sistema de gestão ambiental em } \\
\text { conformidade com a NBR ISO 14001:96, em empresas brasileiras com ações } \\
\text { negociadas na Bovespa, têm impacto positivo em seu desempenho financeiro. } \\
\text { Constataram que a tendência nos resultados de Retorno sobre os Ativos (ROA), } \\
\text { Retorno sobre o Patrimônio Líquido (ROE) e Retorno sobre as Vendas (ROS) é de } \\
\text { aumento no período pós-certificação. Já os indicadores Preço/Lucro (P/L), Preço/Valor } \\
\text { Patrimonial (P/VPA) apresentaram reduções significativas no período pós-certificação. }\end{array}$ \\
\hline $\begin{array}{l}\text { Ott, Alves e Flores } \\
(2009)\end{array}$ & $\begin{array}{l}\text { Constataram que os Investimentos Ambientais Internos (IAI) e os Investimentos } \\
\text { Ambientais Externos (IAE) impactam, de modo significativo, tanto na Receita Líquida } \\
\text { (RL) das empresas quanto no Resultado Operacional (RO). Evidenciaram que os } \\
\text { setores não apresentam características de homogeneidade interna e não há } \\
\text { diferenciação entre setores capaz de explicar o desempenho econômico de outra forma, } \\
\text { sendo o único setor significativo o de petróleo e gás. }\end{array}$ \\
\hline
\end{tabular}

Fonte: os autores.

Jacovine et al. (2009) salientam que a competitividade das organizações não depende apenas de fatores econômicos, mas também de uma gestão socialmente valorizada que garanta a sua legitimidade e sobrevivência no contexto ambiental. Apontam também que o desempenho ambiental de uma empresa é uma consequência de suas práticas competitivas ou dos padrões do comportamento ambiental, que, por sua vez, depende da estrutura do mercado em que se insere. Sobre essas práticas, Donaire (1999, p. 51) salienta que "[...] a ideia que prevalece é de que qualquer providência que venha a ser tomada em relação à variável ambiental traz consigo o aumento de despesas e o consequente acréscimo dos custos do processo produtivo". Ribeiro, Bonfante, Gomes e Cioffi (2009) compactuam com esse pensamento ao enfatizar que a produção com responsabilidade socioambiental gera gastos no sentido de buscar novas tecnologias e, principalmente, coletar e divulgar informações para os agentes interessados na continuidade dos negócios. Todavia, é importante salientar o preconizado por Aragón-Correa e Rubio-López (2007) de que algumas empresas podem melhorar seu desempenho financeiro graças aos progressos na gestão ambiental, mas outras podem obter um melhor desempenho mantendo suas atividades ambientais para atender os requisitos legais mínimos. 


\section{METODOLOGIA}

A estratégia de pesquisa adotada para esta investigação é a de estudo de caso qualitativo da empresa Celulose Irani $\mathrm{S} / \mathrm{A}$, com recortes de pesquisa quantitativa. A escolha da Irani como objeto de estudo se deve a três aspectos fundamentais: (i) ao grau de representatividade da empresa no ramo de papel e celulose (primeira empresa do Brasil a certificar seu Inventário de Gases de Efeito Estufa (GEE), de acordo com a norma ISO 14.064, de 2006, e primeira empresa do Brasil, no setor de papel e embalagem, a ter créditos de carbono emitidos pelo Protocolo de Kyoto); (ii) ao fato de a organização ter desenvolvido o primeiro projeto de MDL no mundo de Tratamento de Efluentes totalmente aeróbicos aprovado pela Organização das Nações Unidas (ONU); (iii) à contribuição analítica do assunto para a academia no contexto dos estudos organizacionais.

Os investimentos ambientais analisados consistem na usina de cogeração de energia e na modernização da estação de tratamento de efluentes (ETE). A análise dos dados tomou como referência o período em que ocorreu o maior volume de investimentos ambientais com foco em dois projetos de MDL. Longitudinalmente, os projetos foram analisados no período selecionado entre 2000 e 2009, que se configuram em três eventos: (i) antes da implantação, entre 2000 e 2003; (ii) durante a implantação, de 2004 a 2007; (iii) após a implantação, entre 2008 e 2009 (Esquema 1).

Esquema 1 - Direcionalidade da Análise Comparativa para os Indicadores Econômico-Financeiros

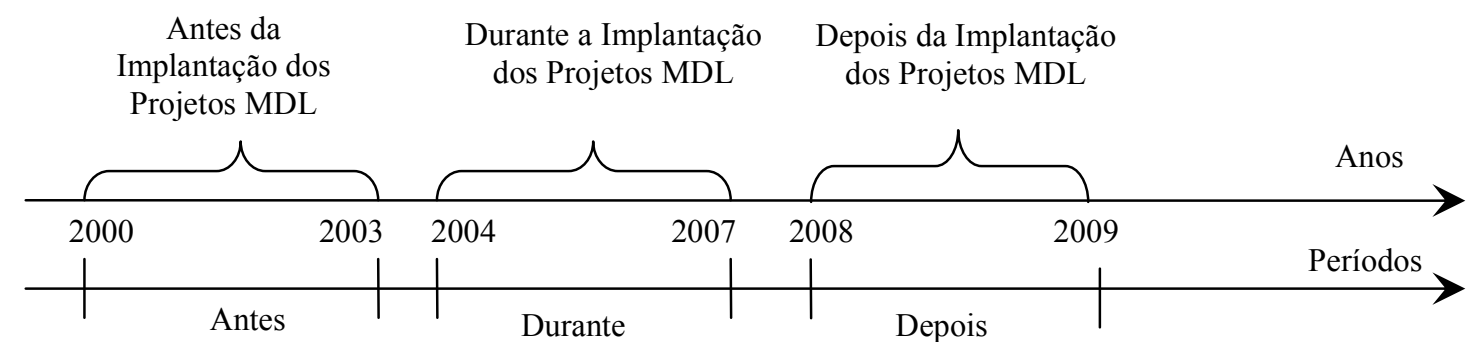

Fonte: os autores.

O período considerado como 'durante', para fins de comparação dos indicadores de desempenho econômicofinanceiro, levou em conta também o interstício do início dos investimentos e o início da operacionalização dos projetos e a aprovação deles pela ONU. Justifica-se a definição desses períodos de implantação dos projetos, conforme mostrado no Esquema 1, para assegurar coerência na 
análise dos indicadores de desempenho financeiro, em relação ao período de investimentos nas tecnologias ambientais.

Com base na teoria, foram selecionadas variáveis indicadoras do desempenho financeiro, que teve o período preestabelecido de 2000 a 2009 para análise. Tais variáveis, em consonância com os objetivos da pesquisa, foram diagnosticadas a partir de dois conjuntos de indicadores.

O primeiro conjunto, fundamentado na dimensão de mercado para a geração de valor econômico e de caixa, constituiu-se dos indicadores Valor Econômico Adicionado (EVA), Valor de Mercado
Adicionado (MVA) e o Earning Before Interest, Taxes, Depreciation and Amortization (EBITDA). $\mathrm{O}$ segundo conjunto de indicadores utilizado no estudo, relacionado com a dimensão da rentabilidade dos investimentos, foi formado por: Retorno sobre o Ativo Total (ROA), Retorno sobre o Investimento (ROI) e Retorno sobre o Patrimônio Líquido (ROE). Para o cálculo desses indicadores, utilizou-se um padrão de operacionalização de acordo com o preconizado no referencial teórico (Quadro $3)$.

Quadro 3 - Medidas de desempenho financeiro baseadas no valor econômico, na geração de caixa e na rentabilidade

\begin{tabular}{|c|c|c|c|}
\hline \multirow{7}{*}{ 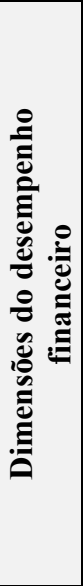 } & \multirow{4}{*}{ Mercado } & Variáveis & Descrição Operacional \\
\hline & & Valor Econômico Adicionado (EVA) & $\begin{array}{l}\text { Lucro Operacional Líquido Depois dos Impostos } \\
\text { (LOLDI) - Custo de Capital Próprio (Patrimônio } \\
\text { Líquido X Taxa SELIC) }^{1}\end{array}$ \\
\hline & & Valor de Mercado Adicional (MVA) & $\begin{array}{l}\text { Valor de mercado da empresa }{ }^{2}-\text { Capital } \\
\text { investido pelos acionistas e terceiros }\end{array}$ \\
\hline & & $\begin{array}{l}\text { Earning Before Interest, Taxes, } \\
\begin{array}{l}\text { Depreciation and Amortization } \\
\text { (EBITDA) }\end{array}\end{array}$ & $\begin{array}{l}\text { Receita bruta - impostos, custos dos produtos e } \\
\text { serviços, despesas com vendas, despesas gerais e } \\
\text { administrativas + despesas com depreciação, } \\
\text { amortização e exaustão. }\end{array}$ \\
\hline & \multirow{3}{*}{$\begin{array}{l}\text { Rentabi- } \\
\text { lidade }\end{array}$} & Retorno do ativo (ROA) & Lucro líquido/ Ativo total médio \\
\hline & & $\begin{array}{l}\text { Retorno sobre o investimento } \\
\text { (ROI) }\end{array}$ & Lucro operacional/ Investimento total médio ${ }^{4}$ \\
\hline & & $\begin{array}{l}\text { Retorno do patrimônio líquido } \\
\text { (ROE) }\end{array}$ & Lucro líquido/Patrimônio líquido médio \\
\hline
\end{tabular}

Fonte: os autores.

Notas: (1) No cálculo do custo de capital próprio, levou-se em conta a taxa Selic, definida pelo Banco Central do Brasil (2010) a partir do percentual do fator acumulado no movimento anual. (2) Para calcular o valor de mercado da empresa, apurou-se o número de ações (Ordinárias Nominativas e Preferenciais Nominativas) disponíveis no mercado e o respectivo valor de fechamento do último negócio de cada ano, acrescido do valor do passivo exigível. (3) No capital investido pelos acionistas e terceiros é considerado o patrimônio líquido juntamente com o passivo exigível. Salienta-se que o passivo exigível não inclui o passivo circulante operacional (fornecedores, salários, impostos, adiantamento a clientes, entre outras contas), pois esse passivo circulante é deduzido diretamente do ativo circulante operacional (HOJI, 2004). (4) No cálculo do investimento total médio, considerou-se o montante do patrimônio líquido acrescido do passivo oneroso da empresa, que traz as dívidas da empresa que produzem custos financeiros (juros). Incluem-se empréstimos, financiamentos, debêntures, entre outras contas (ASSAF NETO; LIMA, 2009, p. 229). 
Os procedimentos de coleta de dados e de análise documental e de conteúdo foram realizados a partir dos dados secundários disponíveis nos relatórios de sustentabilidade e de demonstrações financeiras, divulgados pela empresa. Adicionalmente, foi entrevistado o gerente financeiro da organização, por meio da aplicação de um roteiro de entrevista semiestruturada, para dirimir dúvidas e detalhar aspectos financeiros da organização.

\section{APRESENTAÇÃO E ANÁLISE DOS DADOS}

Neste item são apresentados e discutidos os principais resultados da pesquisa. Primeiramente, mostra-se o perfil da empresa. Em seguida, são descritas as tecnologias ambientais adotadas pela empresa, em especial os projetos usina de cogeração de energia e modernização da ETE. Por último, analisam-se os investimentos ambientais em relação aos indicadores de desempenho financeiro, conforme metodologia e objetivos do estudo.

\subsection{Caracterização da Empresa}

A Celulose Irani S.A. foi fundada em 1941 e é controlada desde 1994 pelo Grupo Habitasul. No ano base, exercício
2009, possui 1.756 colaboradores diretos e cinco unidades fabris, organizadas em três divisões: (i) divisão papel, localizada em Vargem Bonita-SC; (ii) divisão embalagem, que conta com duas unidades produtivas, sendo uma em Vargem BonitaSC e outra em Indaiatuba-SP; (iii) divisão de móveis e resinas, que também conta com duas unidades produtivas, uma fábrica de madeiras reflorestada em Rio NegrinhoSC e uma unidade de negócio, denomina de resinas pela companhia, localizada em Balneário de Pinhal-RS. Possui escritórios em São Paulo-SP, em Joaçaba-SC e matriz em Porto Alegre-RS, e produziu 185 mil toneladas de papel em 2009, tendo obtido R\$ 479,1 milhões de receita bruta em 2009 (CELULOSE IRANI, 2009).

Os produtos produzidos pela Irani são celulose, papéis kraft, chapas e embalagens de papelão ondulado, madeira reflorestada, resinas e móveis de pinus, assegurando o fornecimento de produtos de alta qualidade e de base florestal renovável. A empresa adota o modelo de Relatório de Sustentabilidade, em conformidade com a estrutura, as diretrizes e os protocolos internacionalmente aceitos, no intuito de avançar em direção à transparência e à padronização das informações sobre o seu desempenho. Esse relatório contempla, sobretudo, as dimensões econômica, social e ambiental, o que possibilita a verificação e a validação 
externas e a avaliação aberta dos conteúdos pelos interessados.

A Irani possui, também, 33.221 hectares de terras, localizadas no estado de Santa Catarina, e 13.646 hectares localizados no estado do Rio Grande do Sul. Dessas terras, a empresa mantém 14.843 hectares de florestas nativas em Santa Catarina e 4.587 hectares de vegetação nativa no Rio Grande do Sul. Além disso, a empresa possui um total de 24.571 hectares de florestas plantadas, nos dois estados citados, basicamente do gênero pinus. A prática da produção integrada das florestas plantadas com as matas nativas, por meio de processos adequados de manejo florestal, contribui para a preservação da biodiversidade, gera desenvolvimento econômico - em função da alta produtividade das florestas plantadas - e ainda reduz os níveis de GEE na atmosfera, pelo sequestro de carbono. Os produtos da Irani possuem o Selo Carbono Neutro, que atesta a neutralidade da empresa na emissão de carbono, certificando que suas atividades retiram mais carbono da atmosfera do que emitem. Além disso, a empresa desenvolve projetos de inovação, a exemplo dos projetos de MDL, que contribuíram para a ocorrência de uma redução atestada de gases causadores de efeito estufa, gerando, dessa forma, benefícios globais (CELULOSE IRANI, 2008).
Sob os pilares do desenvolvimento sustentável, a Celulose Irani realizou, em 2007, investimentos em atualizações tecnológicas e ações focadas na busca do alto desempenho econômico. Idealizou e apoiou projetos direcionados à educação $\mathrm{e}$ à preservação ambiental, destacando-se, entre eles, o Inventário de GEE das suas atividades produtivas do ano de 2006, projeto pioneiro no Brasil por obter a certificação referente à norma internacional ISO 14.064. Além disso, a empresa mantém auditores independentes para a verificação da consistência e da integridade de suas operações, os quais emitem pareceres trimestrais e anuais.

\subsection{Tecnologias Ambientais Implantadas na Empresa}

A Celulose Irani desenvolve o seu trabalho com a preocupação da sustentabilidade ambiental, que se operacionaliza por meio de diversas práticas: manejo das florestas até a disposição final dos seus produtos; geração de riqueza e renda, associada à atividade produtiva sustentável; produção a partir de matéria-prima renovável ou reciclada (florestas plantadas e aparas); coleta e tratamento adequados da água, com uso de energia limpa, gerada por meio de fontes renováveis (hidroelétrica e termoelétrica, à base de biomassa); estação de tratamento 
de efluentes; balanço neutro de carbono (cada hectare de floresta plantada captura aproximadamente 8 toneladas de carbono por ano da atmosfera, o que contribui para a diminuição do aquecimento global).

Todo esse trabalho foi reconhecido pela sociedade em 2009, por meio das seguintes premiações: $11^{\circ}$ Prêmio Empresa Cidadã ADVB/SC - ADVBSC: Associação dos Dirigentes de Vendas e Marketing de Santa Catarina (Categoria Preservação Ambiental); Prêmio Fritz Muller (realização da Fatma); $5^{\circ}$ Prêmio Brasil Ambiental Categorias MDL (realização AMCHAM-RIO - Câmara de Comércio Americana do Rio de Janeiro); Prêmio Benchmarking Ambiental Brasileiro (realização Mais Projetos); Prêmio Expressão de Ecologia (Categoria Controle da Poluição Setor Papel e Celulose); Prêmio Febramec 2009 - Feira Brasileira da Mecânica e Automação Industria (Categoria Emissão Atmosférica Gases de Efeito Estufa (GEE)); Prêmio Reabilitação Profissional 2009 (Case Panorama da Reabilitação Profissional na IRANI); e Prêmio Responsabilidade Social 2009 (Realização da Assembleia Legislativa do RS). Conforme o relatório de Sustentabilidade da Celulose Irani (2008), aproximadamente $75 \%$ da demanda energética da empresa foi suprida pela autoprodução proveniente de três hidroelétricas próprias, localizadas no entorno do parque fabril, somadas a uma hidroelétrica movida a biomassa. A biomassa consiste em resíduos florestais produzidos na empresa e por indústrias madeireiras na região. Esses resíduos são convertidos em energia a partir da sua queima como combustível na usina de cogeração. Trata-se da produção de energia limpa. Consequentemente, houve uma redução do consumo de óleo de baixo ponto de fluidez (BPF) em 97\% no período de 2004 a 2008, e foram eliminados os geradores à base de óleo. De acordo com a Celulose Irani (2008), essa ação reduziu significativamente a emissão de GEE.

O Projeto de Inventário de Emissões de GEE realizado pela empresa anualmente, procura identificar as emissões e sumidouros, assim como avaliar o potencial da Irani em relação ao “Carbono Zero", isto é, verificar se a empresa é neutra na emissão de dióxido de carbono, sendo esse processo certificado pela ISO 14064: 2006. Isso comprova que as atividades produtivas da Irani retiram mais carbono da atmosfera do que emitem, tornando a organização Carbono Neutro. $\mathrm{O}$ principal fator que contribuiu para diminuir as emissões diretas foi a ETE da unidade de papel, que reduziu a emissão de metano (CELULOSE IRANI, 2008). A Irani implantou a usina de cogeração em 2004 e modernizou a ETE em 2007, o que corroborou a geração de créditos de 
carbono. Portanto, a redução da emissão de gases de efeito estufa é decorrente de Projetos de MDL de pequena escala. De Sustentabilidade da Celulose Irani (2008, p. 48) “os projetos de MDL possibilitam reduzir a emissão de cerca de 200 mil toneladas de $\mathrm{CO}_{2} \mathrm{e}$ ao ano".

O Projeto da Usina de Cogeração está registrado na ONU sob a terminologia "Irani Biomass Electricity Generation Project" e foi aprovado em 7 de julho de 2006. Esse projeto consiste em geração de eletricidade renovável, que substitui a energia fornecida pela concessionária estadual. Evita a produção de metano pela utilização de combustão controlada de biomassa. Os insumos usados para gerar energia na Usina de Cogeração são originários de resíduos de base florestal que substituem o uso de recursos naturais não-renováveis. Esse procedimento permite reduzir as emissões de gases poluentes, como dióxido de carbono e metano, gerados em maior quantidade na queima de combustíveis fósseis. A implantação desse projeto permitiu a redução atestada de gases poluentes. As reduções certificadas de emissões (CER), obtidas entre 2005 e 2008, totalizaram 567.214 toneladas de $\mathrm{CO} 2 \mathrm{e}$ (equivalent carbon dioxide). Levando-se em conta a média obtida nos últimos dois anos, a estimativa de redução de emissão de gás acordo com o Relatório de

carbônico pela Irani em 21 anos é de aproximadamente 3.321 .885 toneladas de CO2e (CELULOSE IRANI, 2008).

A Modernização da ETE foi o primeiro projeto no mundo de tratamento de efluentes totalmente aeróbicos aprovado pela ONU. A degradação anaeróbica (sem oxigenação) foi substituída pela aeróbica (com oxigenação) da matéria orgânica, o que evita a emissão de metano, um gás de efeito estufa responsável pelo aquecimento global. Esse sistema baseia-se no tratamento secundário a partir do lodo ativado com aeração prolongada, o que contribui para que o lodo não se deposite no fundo da lagoa e gere metano. "As Reduções Certificadas de Emissões (CER) obtidas entre 2007 e 2008, totalizaram 59.807 toneladas de $\mathrm{CO}_{2}$ e. Considerandose a média obtida em 2008, a estimativa de redução de emissão de gás carbônico pela Irani em 21 anos, decorrente desse projeto, é de aproximadamente 821.100 toneladas de $\mathrm{CO}_{2} \mathrm{e} "$ (CELULOSE IRANI, 2008, p. 49).

\subsection{Investimentos em Tecnologias Ambientais e Desempenho Econômico-} Financeiro da Empresa

Neste tópico apresentam-se e
discutem-se os investimentos em
tecnologias ambientais; a evolução dos
indicadores baseados nos valores

estão. Vol $12-\mathrm{N}^{\circ} 1-$ jan/abr 2014

Neste tópico apresentam-se e 71 CONTEXTUS Revista Contemporânea de Economia e Gestão. Vol 12 - No 1 - jan/abr 2014 
econômicos (EVA e MVA) e na geração de caixa (EBITDA); os indicadores de rentabilidade (ROA, ROI e ROE), em relação ao período de análise.

$\mathrm{Na}$ Figura 1, são mostrados os investimentos totais em tecnologias ambientais, com destaque para os projetos 'usina de cogeração de energia' e 'modernização da estação de tratamento de efluentes', realizados pela empresa desde 2003. Para cada projeto indicam-se também os resultados dessas tecnologias e os créditos de carbono, que são receitas advindas de ambos os projetos aprovados pela ONU.

Figura 1 - Investimentos em tecnologias ambientais (2003-2009) e créditos de carbono (receitas anuais)

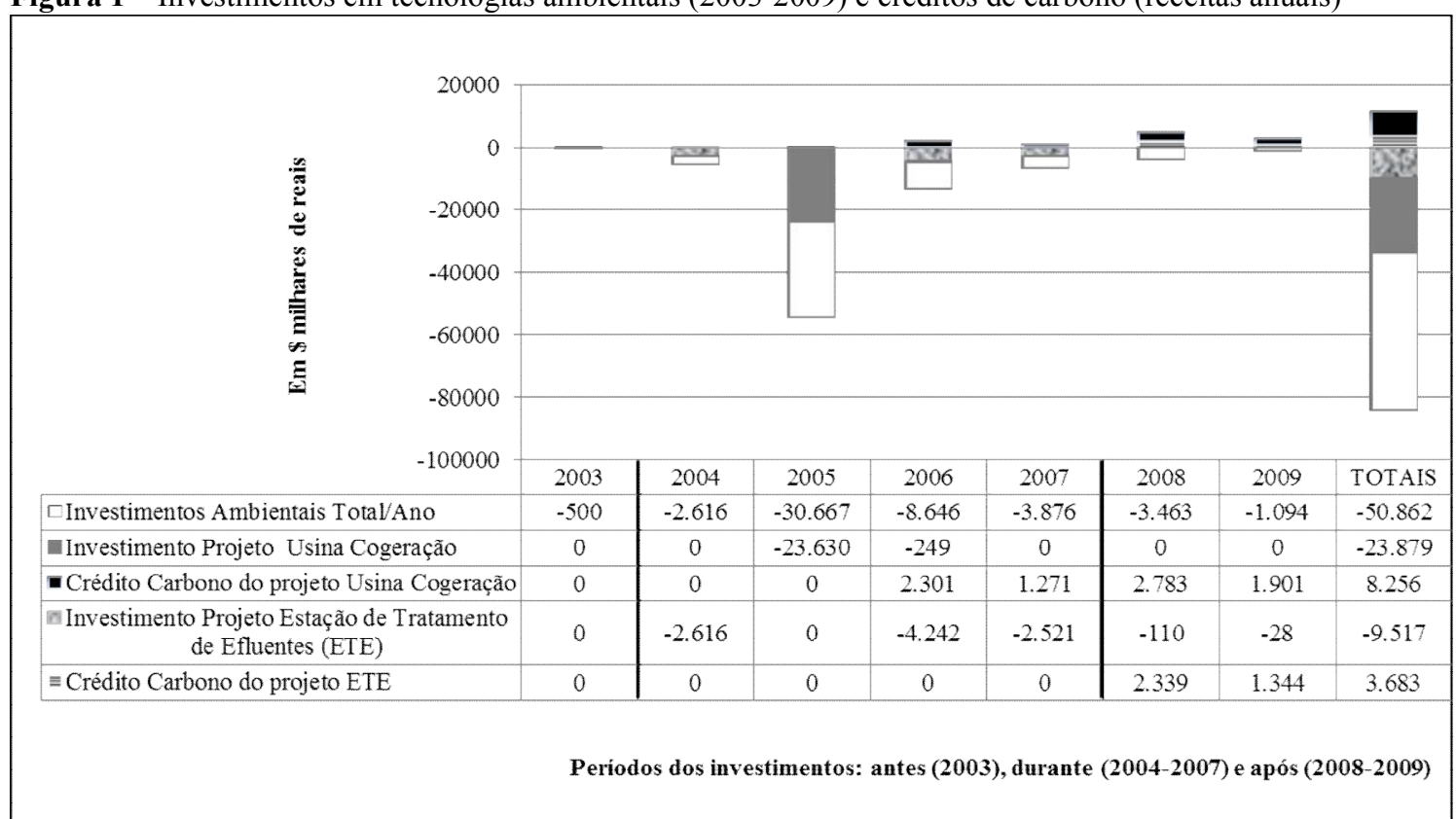

Fonte: os autores.

Pela Figura 1 é possível constatar que do total de investimentos em tecnologias ambientais realizados pela empresa, desde 2003, aproximadamente $70 \%$ corresponde aos projetos usina de cogeração e modernização da estação de tratamento de efluentes (ETE), sendo o primeiro $o$ de maior investimento. Entretanto, a partir de 2006, começaram a ingressar os créditos de carbono do projeto da usina de cogeração. É a partir desse momento que a Celulose Irani passa a receber os primeiros retornos financeiros dos investimentos ambientais despendidos durante o período de implantação. Em relação ao projeto de modernização ETE, os créditos de carbono iniciam em 2008.

A evolução dos indicadores baseados no valor econômico e na geração de caixa, em relação aos períodos de investimentos em tecnologias ambientais, é apresentada na Figura 2. 
Figura 2 - Evolução dos indicadores baseados no valor econômico e na geração de caixa em relação aos períodos de investimentos em tecnologias ambientais

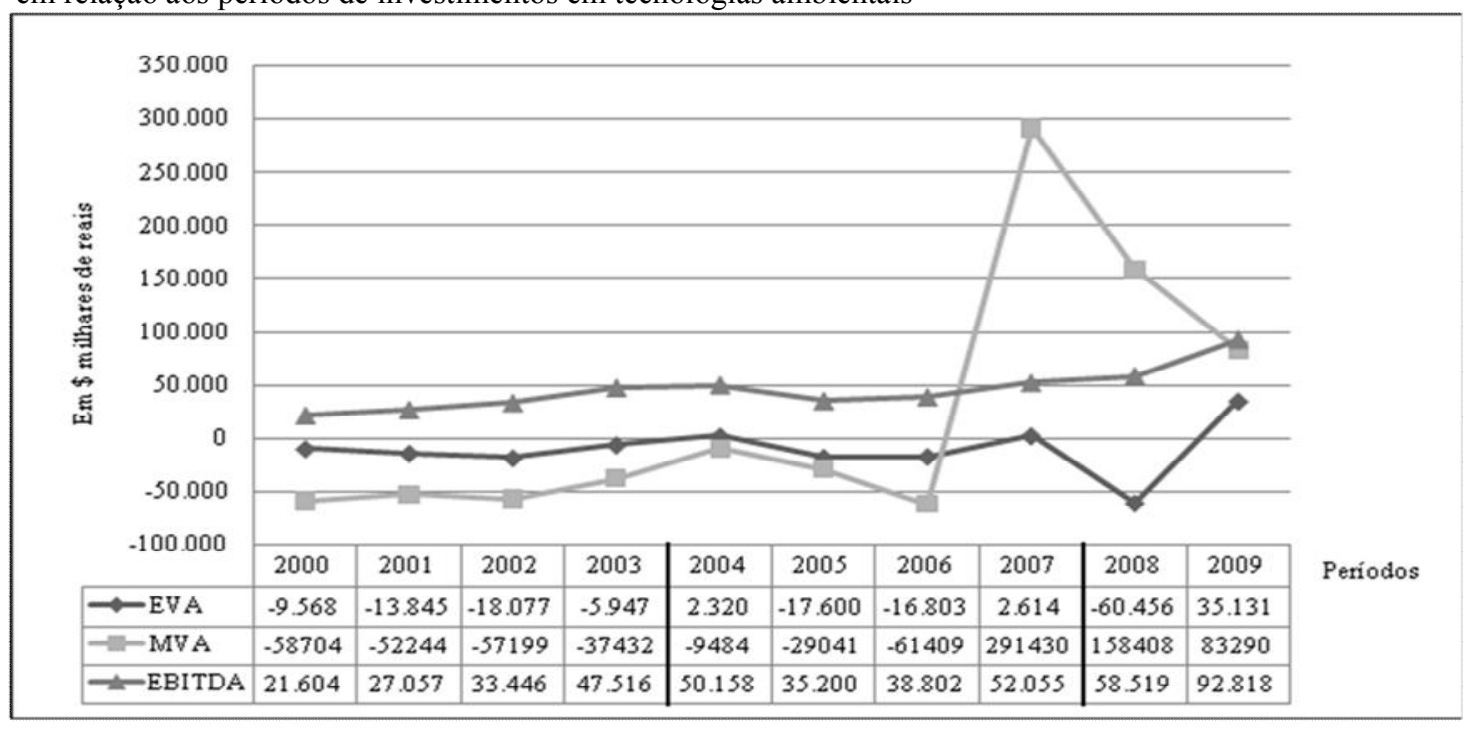

Fonte: os autores.

Na Figura 2, evidencia-se que nos quatro anos anteriores aos investimentos efetuados na usina de cogeração e na estação de tratamento de efluentes, isto é, no período de 2000 a 2003, a Celulose Irani S.A. obteve um EVA negativo. Durante o período de investimentos ambientais, ou seja, de 2004 a 2007, as oscilações do EVA foram abruptas, correspondendo a uma variação de $\mathrm{R} \$$ 2.320 mil em 2004 para $\mathrm{R} \$ 17.600$ mil em 2005; e ainda $\mathrm{R} \$ 16.803$ mil no ano de 2006 e um comportamento positivo de R\$ 2.614 mil em 2007. Observa-se que essas variações estão associadas ao lucro do exercício da empresa. Em 2005 e 2006, o lucro teve uma forte redução em relação aos anos anteriores, o que causou impacto no EVA. De acordo com o relatório da administração, publicado nos balanços de
2005 e 2006, a excessiva apreciação do Real nesse período ocasionou maior oferta de produtos no mercado interno, que refletiu em uma queda significativa nos preços e nas margens líquidas, impactando fortemente no resultado da Irani.

No período seguinte, após os investimentos ambientais (2008-2009), é verificado um padrão ainda mais súbito, de $\mathrm{R} \$ 60.456$ mil em 2008 para $\mathrm{R} \$ 35.131$ mil em 2009, que - na percepção do entrevistado - está associado à crise financeira internacional e à conclusão do Projeto Superação, em 2008, onde foram alocados $\mathrm{R} \$ \quad 160,8$ milhões na modernização das fábricas de papel e embalagem. Nota-se que o resultado do EVA desse último ano foi o maior em todos os períodos analisados. Portanto, ficou evidenciado que o valor do EVA 
sofreu alterações que não permitem estabelecer um padrão histórico de evolução nos períodos analisados. A variação foi grande e discrepante, o que dificulta a verificação e a afirmação da existência de uma tendência central, isto é, um padrão de comportamento ascendente ou descendente ao longo dos anos em relação aos períodos de investimentos nas tecnologias ambientais.

O MVA mostra um comportamento similar ao EVA na maioria dos períodos, porém com um crescimento expressivo em 2007 e, embora tenha se reduzido nos anos seguintes, 2008 e 2009, o indicador manteve-se positivo. Tais resultados são similares aos encontrados por Santos e Watanabe (2005), que elucidaram em seu estudo uma diferença fundamental entre os índices EVA e MVA. Enquanto o primeiro índice se baseia nos demonstrativos contábeis e reflete o desempenho passado da empresa, o segundo revela a visão do mercado de capitais, incorporando a expectativa de resultados futuros da companhia. Os autores salientam que, em princípio, não há uma relação direta entre o EVA passado da organização e o MVA. Mas, caso uma empresa apresente uma melhora no EVA apurado num determinado período e o mercado entenda que essa melhora vai perdurar no futuro, então esse acréscimo de performance deverá se refletir imediatamente no MVA da empresa, o que parece ter ocorrido na Celulose Irani S.A. De acordo com o entrevistado e com base nos balanços financeiros de 2006 e de 2007 (além dos respectivos balanços sociais e relatórios de sustentabilidade), a empresa informou o mercado sobre os resultados advindos do projeto de cogeração de energia sob a forma de créditos de carbono e sobre o 'Projeto Superação', que incluía investimentos em tecnologias ambientais visando a otimização de recursos existentes, além dos benefícios ambientais.

Acerca do comportamento do EBITDA, nos anos de 2000 a 2009, é possível constatar, na Figura 3, que esse indicador mais que quadruplicou no período, passando de R $\$ 21.604$ mil para R\$ 92.818 mil. Evidencia-se também que essa evolução se deu ano a ano, com exceção de 2005, quando houve uma queda de $70,18 \%$ em relação ao EBITDA de 2004, que retomou o crescimento em 2006. Análogo ao comportamento verificado no MVA, o EBITDA também parece ter sido influenciado pelas tecnologias ambientais, principalmente no período após os investimentos. Essa inferência encontra suporte no conceito do EBITDA, o qual indica se os ativos operacionais estão gerando caixa. Como a usina de cogeração e a ETE resultaram em créditos de carbono, cujas receitas advindas dos projetos iniciaram já em 2006, presume-se 
que parte do crescimento do EBITDA tenha relação com esses ativos. Todavia, essas evidências não podem ser comprovadas suficientemente apenas com os dados coletados e analisados neste artigo. Outras variáveis ou externalidades, como o Projeto Superação, salientado anteriormente, podem ter contribuído para o alcance desse comportamento nos períodos analisados, sobretudo no período considerado após os investimentos nas tecnologias ambientais. A Figura 3 apresenta a evolução dos indicadores de rentabilidade em relação aos períodos de investimentos em tecnologias ambientais.

Figura 3 - Evolução dos indicadores de rentabilidade em relação aos períodos de investimentos em tecnologias ambientais

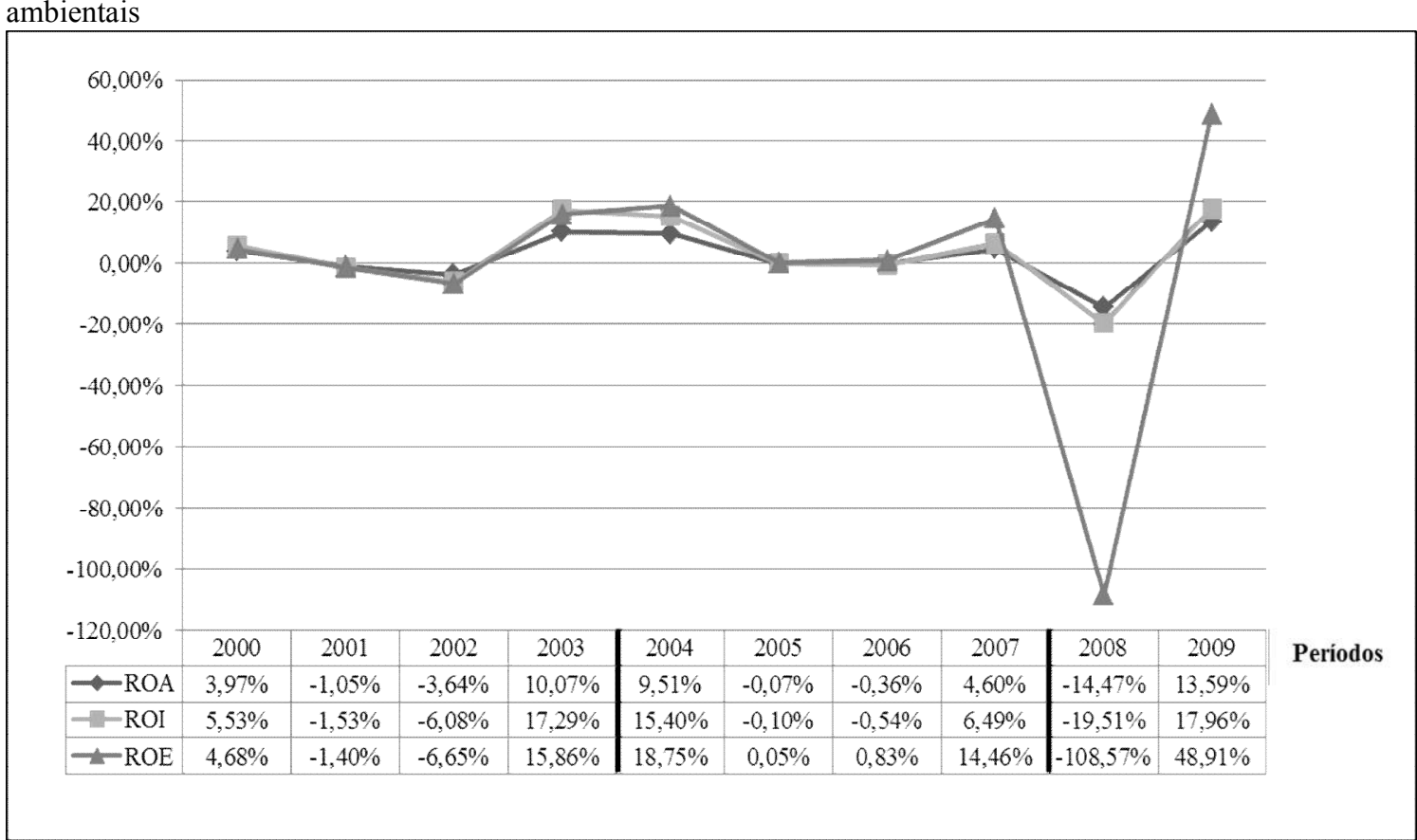

Fonte: os autores

Nota-se que há um comportamento similar, em todos os períodos, entre os três indicadores de rentabilidade analisados. $\mathrm{O}$ ROA variou de 3,97\% em 2000 para $13,59 \%$ em 2009, ao passo que o ROI variou de $5,53 \%$ para $17,96 \%$. A maior variação ocorreu com o ROE, que estava com 4,68\% em 2000 e evoluiu para um índice de 48,91\% em 2009. Por outro lado, esse mesmo indicador, após finalizar os investimentos ambientais em análise, apresenta também a maior queda $(108,57 \%)$. Infere-se, pois, que essa discrepância, se comparada aos anos anteriores, pode estar associada à crise financeira internacional, que impactou negativamente em todas as atividades econômicas, assim como à desvalorização do real, principalmente no ano de 2008. 
De toda forma, esse conjunto de indicadores parece ser menos sensível aos investimentos em tecnologias ambientais, comparativamente aos indicadores baseados no valor econômico e de geração de caixa, com destaque para o MVA e o EBITDA. Embora o ano de 2008 tenha sido atípico ao longo do período estudado, não é possível identificar um padrão de associação dos indicadores de rentabilidade em relação aos diferentes períodos de implantação dos projetos de MDL analisados. Esse resultado converge para o achado de estudos anteriores, como Wagner et al., (2002) e Thornton, Kagan e Gunningham (2003), que também estudaram investimentos ambientais e desempenho financeiro em indústrias de papel, medido pela rentabilidade, e não encontraram relação entre essas variáveis.

\section{CONSIDERAÇÕES FINAIS}

O propósito do artigo consistiu em analisar o impacto das tecnologias ambientais no desempenho econômicofinanceiro de uma empresa de papel e celulose. São tecnologias que visam minimizar ou neutralizar possíveis impactos no meio ambiente e que se coadunam com a política de mitigar os impactos ambientais durante o processo produtivo. Constata-se que os principais investimentos ambientais efetuados pela empresa consistem na usina de cogeração e na modernização da ETE. Esses investimentos parecem ter impactado favoravelmente no desempenho econômico-financeiro da organização, levando-se em conta somente os indicadores de valor econômico e de geração de caixa, em específico o MVA e o EBITDA.

Contudo, o mesmo desempenho desses indicadores não ocorre em todos os períodos de análise. Considerando os demais indicadores, sobretudo os de rentabilidade (ROA, ROI e ROE), a associação com os investimentos ambientais é ainda menos sensível. Esse desempenho pode estar relacionado à crise econômica mundial que se deflagrou no período (a partir de setembro de 2008) e à queda significativa nos preços e nas margens líquidas da empresa em 2005 e 2006 em razão da forte apreciação do Real, e que impactaram nos indicadores financeiros analisados, ocasionando grandes oscilações nas variáveis sistematizadas.

Sob uma percepção imediatista, constata-se que os investimentos ambientais acarretam custos extras, e, por conseguinte, reduzem o resultado operacional. E, ainda, a desvalorização do real no ano de 2008 teve forte impacto no resultado da empresa Irani, principalmente no ano de 2008, em decorrência da 
atualização de empréstimos e financiamentos denominados em dólar e em euro (CELULOSE IRANI, 2008).

Conforme Release de Resultados da empresa (CELULOSE IRANI, 2009), o ano de 2009 consagrou a consolidação dos investimentos feitos em 2007 e 2008 e do início da captura dos seus benefícios. Apesar da crise, as margens de geração de caixa da empresa cresceram substancialmente, bem como cresceu o market-share no segmento de papelão ondulado. Também em 2009 foram implementadas medidas de redução de custos em todas as unidades, para buscar adequá-las.

Portanto, infere-se que tais dados não permitem estabelecer uma tendência de comportamento ascendente ou descendente ao longo dos anos, para os indicadores analisados. Diante dos resultados, a empresa situa-se em um patamar que está mais próximo da satisfação dos stakeholders, os quais defendem que a organização precisa assumir múltiplos objetivos e não apenas perseguir a maximização da riqueza dos acionistas. Entretanto, essa percepção se dá a partir de um cenário econômico mundial em recessão, 2008 e 2009, que coincide com o período pós-implantação das tecnologias ambientais. Considerando que os investimentos, em geral, apresentam retorno no médio e longo prazo, pode-se deduzir que os indicadores analisados mostram um desempenho financeiro superior ao longo dos anos.

A prática de investir em tecnologias ambientais condiz com a política de atuação da empresa, cuja missão consiste em "Gerar valor para nossos clientes, fornecendo com segurança e excelência serviços e produtos de base florestal renovável, com absoluto respeito ao meio ambiente $\mathrm{e}$ às pessoas, garantindo a sustentabilidade dos nossos negócios, com crescimento justo e permanente retorno aos investidores”. As práticas da Irani estão aliadas, sobretudo, aos princípios de sustentabilidade, tendo sido a primeira empresa brasileira do setor de papel e celulose e a segunda no mundo a possuir créditos de carbono emitidos pelo Protocolo de Kyoto.

As limitações do estudo consistem em: utilização de uma única empresa; espaço temporal de 10 anos de análise (4 antes, 4 durante e 2 depois da implantação dos projetos ambientais usina de cogeração e modernização da estação de tratamento de efluentes). Salienta-se, ainda, que o desempenho econômico-financeiro pode estar associado a um conjunto de outros fatores, que não somente os investimentos ambientais.

Sugerem-se, para futuras pesquisas: comparar a empresa com outras organizações do setor para identificar 
similitudes comportamentais e econômicas; investigar a eficiência dos investimentos ambientais, o potencial de retorno econômico da neutralização de créditos de carbono e os benefícios sociais decorrentes das práticas de redução da emissão de metano; pesquisar se o valor de mercado das firmas que possuem reputação ambiental é maior; correlacionar o desempenho ambiental com o valor dos ativos da firma.

\section{REFERÊNCIAS}

ALBERTON, A.; COSTA JR., N. C. A. Meio ambiente e desempenho econômicofinanceiro: benefícios dos sistemas de gestão ambiental (SGAs) e o impacto da ISO 14001 nas empresas brasileiras. RAC Eletrônica, v. 1, n. 2, art. 10, p. 153-171, maio/ago. 2007.

\section{ALBERTON, A. Meio ambiente e desempenho econômico-financeiro: impacto da ISO 14001 nas empresas brasileiras. 2003. 285 f. Tese (Doutorado em Engenharia de Jaggi e Freedman Produção) -Universidade Federal de Santa Catarina, Florianópolis, 2003.}

ARAGÓN-CORREA, J. A.; RUBIOLÓPEZ, E. A. Proactive corporate environmental strategies: myths and misunderstandings. Long Range Planning, v. 40, n. 3, p. 357-381, June 2007.

ASSAF NETO, A.; LIMA, F. G. Curso de administração financeira. São Paulo: Atlas, 2009.

BANCO CENTRAL DO BRASIL. Taxa Selic. Disponível em:
$<$ http://www.bcb.gov.br>. Acesso em: 23 abr. 2010.

BANSAL, P. Evolving sustainability: a longitudinal study of corporate sustainable development. Strategic Management Journal, v. 26, n. 3, p. 197-218, Mar. 2005.

BESANKO, D. DRANOVE, D; SHANLEY, M.; SCHAEFER, S. A economia da estratégia. 3 . ed. São Paulo: Bookman, 2006.

BRASIL. Lei $\mathrm{N}^{\mathrm{O}} 10.165$, de 27 de Dezembro de 2000. Presidência da República. Casa Civil, Sub-Chefia de Assuntos Jurídicos. Disponível em: $<$ http://www.planalto.gov.br/ccivil_03/Lei s/L10165.htm>. Acesso em: 23 abr. 2010.

BRITO, E. P. Z.; MORGANTI, F.; BRITO, L. A. L. Inovação e o desempenho empresarial: lucro ou crescimento? RAEeletrônica, v. 8, n. 1, jan./jun. 2009.

CARDOSO, L. F.; MARINHO, M. M. Indicadores de produção limpa: uma proposta para análise de relatórios ambientais de empresas. In: KIPERSTOK, A. (Org.). Prata da casa: construindo a produção limpa na Bahia. Salvador: Universidade Federal da Bahia, 2008. p. $45-58$

CELULOSE IRANI. Relatório de Sustentabilidade. 2008. Disponível em: $<$ http://www.irani.com.br/estrutura.php?id=1 $0 \&$ inst $=97>$. Acesso em: 10 jan. 2010 .

CELULOSE IRANI. Release de Resultados. 2009. Disponível em:

$<$ http://www.irani.com.br/ri/>. Acesso em 5 abr. 2010.

CORAZZA, R. Economia, tecnologia e meio ambiente: comentários sobre aspectos positivos e normativos da economia e do meio ambiente. Ensaios FEE, Porto Alegre, v. 24, n. 2, p. 479-498, 2003. 
DONAIRE, D. Gestão Ambiental na

Empresa. 2. ed. São Paulo: Atlas, 1999.

ECONOMÁTICA. Disponível em:

$<\mathrm{http} / /$ www.economatica.com/pt/base_da

dos.html>. Acesso em: 6 out. 2009.

GASI, T. M. T.; FERREIRA, E. Produção mais limpa. In: VILELA JUNIOR, A.; DEMAJOROVIC, J. (Org.). Modelos e ferramentas de gestão ambiental: desafios e perspectivas para as organizações. São Paulo: editora Senac, 2006.

GONÇALVES, R. B. Aplicação de tecnologia de produção mais limpa no setor metal-mecânico: um estudo de caso. 1998. 101 f. Dissertação (Mestrado em Administração) - Universidade Federal do Rio Grande do Sul, Porto Alegre, 1998.

GRAVONSKI, I. Impacto das Decisões Tecnológicas Ambientais no Desempenho de Operações. In: ENCONTRO ANUAL DA ASSOCIAÇÃO NACIONAL DOS PROGRAMAS DE PÓS-GRADUAÇÃO EM ADMINISTRAÇÃO (ENANPAD), 33., 2009, São Paulo (SP). Anais... São Paulo: Anpad, 2009. CD-ROM.

HART, S. L.; AHUJA, G. Does it pay to be green? An empirical examination of the relationship between emission reduction and firm performance. Business Strategy and the Environment, v. 5, p. 30-37, 1996.

HOJI, M. Administração financeira: uma abordagem prática... 5. ed. São Paulo: Atlas, 2004.

JACOVINE, L. A. G. et al. Environmental approach of companies within the pulp/paper, metallurgical and sugar/alcohol sectors. Sci. Agric. (Piracicaba, Braz.), v. 66, n. 1, p. 1-7, Jan./Feb. 2009.

JAGGI, B.; FREEDMAN, M. An examination of the impact of pollution performance on economic and market performance: pulp and paper firms.
Journal of Business Finance and Accounting, v. 19, n. 5, p. 697-713, 1992.

KEATS, B. W.; HITT, M. A. A causal model of linkages among environmental dimensions, macro organizational characteristics, and performance. Academy of Management Journal, v. 31, n. 3, p. 570-598, Sept.1. 1988.

KRAMER, J. K.; PUSHNER, G. An empirical analysis of economic value added as a proxy for market value added. Financial Practice \& Education, v. 7, n. $1,1997$.

KING, A. A.; LENOX, M. J. Does it really pay to be green? An empirical study of firm environmental and financial performance. Journal of Industrial Ecology, v. 5, n. 1, 2001.

KLASSEN, R. D.; MCLAUGHLIN, C. P. The impact of environmental management on firm performance. Management Scienc, v. 42, n. 8, Aug. 1996.

LEMOS, A. D. da C. Produção mais limpa como geradora de inovação $e$ competitividade: o caso da fazenda Cerro do Tigre. 1998. 182 f. Dissertação (Mestrado em Administração) Universidade Federal do Rio Grande do Sul, Porto Alegre, 1998.

MAZON, R. Em direção a um novo paradigma de gestão ambiental: tecnologias limpas ou prevenção de poluição. Revista de Administração de Empresas, v. 32, n. 2, p. 78-98, abr./jun.1992.

MELLO, M. C. A. de. Produção mais limpa: um estudo de caso na AGCO do Brasil. 2002. 113 f. Dissertação (Mestrado em Administração) - Universidade Federal do Rio Grande do Sul, Porto Alegre, 2002.

OLSON, R. L. The greening of hight-tech. The futurist, v. 25, n. 3, p. 28-34, May/June, 1991. 
OTT, E.; ALVES, T. W.; FLORES, G. S. da $\mathrm{S}$. Investimentos ambientais e o desempenho econômico das empresas: um estudo utilizando dados em painel. In:

ENCONTRO ANUAL DA ASSOCIAÇÃO NACIONAL DOS PROGRAMAS DE PÓS-GRADUAÇÃO EM ADMINISTRAÇÃO (ENANPAD), 33., 2009, São Paulo (SP). Anais... São Paulo: Anpad, 2009. CD-ROM.

PERIN, M. G.; SAMPAIO, C. H. Orientação para o mercado, porte empresarial e performance. ERA Revista de Administração de Empresas, São Paulo, v. 44, n. 3, p. 76-88, 2004.

PORTER, M.; VAN DER LINDE, C. Toward a new conception of the environment-competitiveness relationship. The Journal of Economics Perspectives, v. 9, n. 4, p. 97-118, 1995.

PORTER, M. E. Competitive Advantage. New York: Free Press, 1985.

RIBEIRO, M. de S.; BONFANTE, T. M.; GOMES, C. C. M. P.; CIOFFI, J. L. Responsabilidade socioambiental no setor de papel e celulose. In: ENCONTRO ANUAL DA ASSOCIAÇÃO NACIONAL DOS PROGRAMAS DE PÓSGRADUAÇÃO EM ADMINISTRAÇÃO (ENANPAD), 33., 2009, São Paulo (SP). Anais... São Paulo: Anpad, 2009. CDROM.

SANTOS, J. B. Uma proposta de conceituação e representação do desempenho empresarial. 2008. 126p. Dissertação (Mestrado em Administração de Empresas) - Escola de Administração de Empresas de São Paulo da Fundação Getúlio Vargas, São Paulo, 2008.
SANTOS, J. O. dos; WATANABE, R. Uma análise da correlação entre o EVA e o MVA no contexto das empresas brasileiras de capital aberto. Caderno de Pesquisas em Administração, São Paulo, v. 12, n. 1, p. 19-32, jan./mar, 2005.

\section{SEIFFERT, M. E. B. Mercado de} carbono e Protocolo de Quioto: oportunidades de negócios na busca da sustentabilidade. São Paulo: Atlas, 2009.

TIGRE, P. B. (Coord.). Tecnologia e meio ambiente: oportunidades para a indústria. Rio Janeiro: UFRJ, 1994.

THORNTON, D.; KAGAN, R. A.; GUNNINGHAM, N. Sources of corporate environmental performance. California Management Review, v. 46, n. 1, 2003.

TRIVIÑOS, A. N. S. Introdução à pesquisa em ciências sociais: a pesquisa qualitativa em educação. São Paulo: Atlas, 1987.

VENKATRAMAN, N.; RAMANUJAM, $\mathrm{V}$. Measurement of business performance in strategy research: a comparison of approaches. Academy of Management Review, v. 11, n. 4, 1986.

WAGNER, M.; VAN PHU, N.; AZOMAHOU, T.; WHERMEYER, W. The relationship between the environmental and economic performance of firms: an empirical analysis of the European paper industry. Corporate Social-Responsibility and Environmental Management, v. 9, n. 3, p. 133-146, Sept. 2002.

YIN, R. K. Estudo de caso: planejamento e métodos. 3. ed. Porto Alegre: Bookman, 2005. 